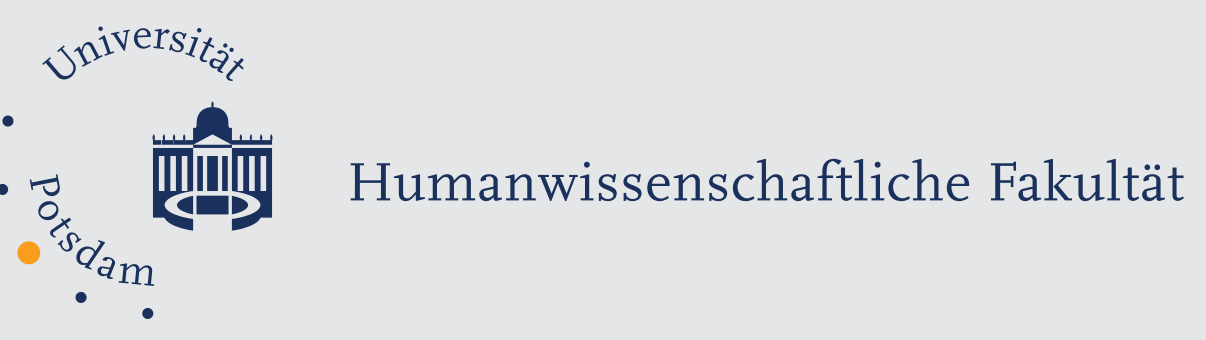

Anja Hirschmueller | Heiner Baur | Sepp Braun | Peter C. Kreuz Norbert P. Suedkamp | Philipp Niemeyer

\title{
Rehabilitation after autologous chondrocyte implantation for isolated cartilage defects of the knee
}

Suggested citation referring to the original publication:

American journal of sports medicine 39(12), 2011, pp. 2686-2696

DOI http://dx.doi.org/10.1177/0363546511404204

ISSN (print) 0363-5465

ISSN (online) 1552-3365

Postprint archived at the Institutional Repository of the Potsdam University in:

Postprints der Universität Potsdam

Humanwissenschaftliche Reihe ; 367

ISSN 1866-8364

http://nbn-resolving.de/urn:nbn:de:kobv:517-opus4-403170 



\title{
Rehabilitation After Autologous Chondrocyte Implantation for Isolated Cartilage Defects of the Knee
}

\author{
Anja Hirschmüller, ${ }^{\star \dagger}$ MD, Heiner Baur, ${ }^{\ddagger}$ PhD, Sepp Braun, ${ }^{\dagger} M D$, Peter C. Kreuz, ${ }^{\|} M D, P h D$, \\ Norbert P. Südkamp, ${ }^{\dagger}$ MD, PhD, and Philipp Niemeyer, ${ }^{\dagger}$ MD, PhD
}

Autologous chondrocyte implantation for treatment of isolated cartilage defects of the knee has become well established. Although various publications report technical modifications, clinical results, and cell-related issues, little is known about appropriate and optimal rehabilitation after autologous chondrocyte implantation. This article reviews the literature on rehabilitation after autologous chondrocyte implantation and presents a rehabilitation protocol that has been developed considering the best available evidence and has been successfully used for several years in a large number of patients who underwent autologous chondrocyte implantation for cartilage defects of the knee.

Keywords: autologous chondrocyte implantation; cartilage repair; cartilage defect; cell transplantation; knee joint; rehabilitation

Autologous chondrocyte implantation (ACI) was introduced in 1994 by the Lars Peterson group as an innovative cell-based treatment for isolated and circumscribed cartilage defects of the knee. ${ }^{16,50}$ The procedure is indicated for symptomatic International Cartilage Repair Society (ICRS) grade III or IV lesions that are 2 to $3 \mathrm{~cm}^{2}$ (Figure 1). In the meantime, various modifications of the original technique have been introduced that have helped to improve clinical results and reduce the incidence of characteristic complications, while making the application of ACI easier (Figures 1 and 2). ${ }^{6,27,30,49,63,65}$

Nevertheless, researchers have continued to put their major focus on the surgical technique over the past decade. In contrast to this, many authors emphasize the importance of adequate postoperative rehabilitation being an essential part of successful cartilage repair using ACI. ${ }^{17,29,31,43}$ However, clinical and scientific evidence concerning rehabilitation after ACI is still elusive. ${ }^{21,69}$

As for most knee surgeries, return to full weightbearing, the restitution of preoperative range of motion (ROM), the restoration of muscle strength, and the recovery of neuromuscular control are the primary goals of postoperative care after chondral restorative procedures of the knee. In ACI, the rehabilitation measures used to achieve these

*Address correspondence to Anja Hirschmüller, MD, Hugstetterstrasse 55, Freiburg 79106, Germany (e-mail: anja.hirschmueller@uniklinikfreiburg.de).

${ }^{\dagger}$ University Hospital Freiburg, Department of Orthopedic Surgery and Traumatology, Freiburg, Germany.

‡University Outpatient Clinic, Sports Medicine and Sports Orthopedics, University of Potsdam, Potsdam, Germany.

§Bern University of Applied Sciences, Health, Bern, Switzerland.

"University Medical Center Rostock, Department of Orthopedic Surgery, Rostock, Germany.

The authors declared that they have no conflicts of interest in the authorship and publication of this contribution.

The American Journal of Sports Medicine, Vol. 39, No. 12 DOI: $10.1177 / 0363546511404204$

(C) 2011 The Author(s) goals have to be oriented toward the biologic remodeling of the repair tissue. As it is well known that the process of cartilage regeneration and differentiation takes up to 3 years, ${ }^{13}$ the rehabilitation process is often time-consuming and challenging for patients and therapists. The satisfying return to sports rates and especially the high durability of sports participation of $96 \%$ after autologous chondrocyte transplantation $^{44}$ show that it is, nevertheless, worthwhile to advocate ACI in even high-level athletes.

As surgical complications and failure of cartilage regeneration, including delamination, transplant hypertrophy, or insufficient fusion, might sometimes be attributed to inappropriate rehabilitation progress, ${ }^{45}$ a close individual guidance of the patient as well as good interdisciplinary teamwork are important for postoperative rehabilitation.

This article summarizes the literature available on rehabilitation after ACI for cartilage defects of the knee joint and presents a rehabilitation scheme that has been used in our department for several years and has proven to be reliable, efficient, and reproducible. ${ }^{27,48,64}$ The rehabilitation regimen was derived from the best evidence available. We are aware of a lack of scientific proof for several recommendations given in this article and therefore encourage clinical and preclinical studies on this topic that might help to optimize rehabilitation and clinical outcome after ACI.

\section{GRAFT REMODELING AND CONSEQUENCES FOR THE REHABILITATION PROCESS}

With regard to the graft remodeling process and graft maturation, different phases of postoperative treatment and rehabilitation can be distinguished. Although most surgeons base their rehabilitation protocol after ACI on personal experience and individual, patient-specific factors, the following biologic basics of the technique will guide the rehabilitation process. 


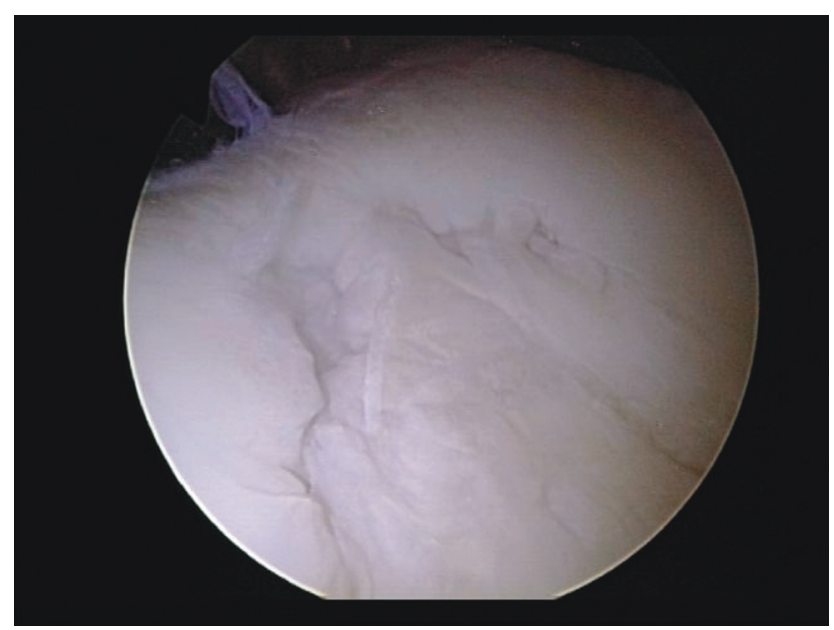

Figure 1. A full-thickness defect of the trochlea (grade III according to the International Cartilage Repair Society, size $2 \mathrm{~cm} \times 1.5 \mathrm{~cm}$ ), which is eligible for autologous chondrocyte implantation.

The first 4 to 6 weeks are characterized by cell adhesion, tissue fill of the defect, and production of specific matrix markers. This stage is called the proliferation phase. A bovine animal model has been used to demonstrate that transplanted chondrocytes attach themselves to the underlying surface as early as 4 hours postoperatively. Positioning of the patient can guide their direction of migration. ${ }^{62}$ During the first weeks after the transplantation, the consistency of the defect fill is fluid-like. It is thus obvious that shear forces will be deleterious to the transplant at that stage. On the other hand, it is well known from the literature that joint mobilization and partial loading is vital for the nutrition of the chondrocytes, which is provided by diffusion of synovial fluid. ${ }^{18,67}$ Passive ROM exercises should, therefore, postoperatively start as soon as tolerated, usually on day 1. Passive joint mobilization can be achieved either by using continuous passive motion (CPM) (Figure 3A), an isokinetic device, or by manual mobilization of the joint (Figure 3B). ${ }^{31,55} \mathrm{~A}$ study on patients having microfracture procedures showed an $85 \%$ satisfactory outcome in patients using a CPM machine for 6 to 8 hours per day for 8 weeks, as compared with $55 \%$ satisfactory outcome in those patients who did not use a CPM machine. ${ }^{59}$

Clinically, the proliferation phase is characterized by wound healing, step-wise resorption of the intra-articular effusion, and the restoration of joint homeostasis. This can well be supported by cryotherapy and joint mobilization. As cryotherapy positively influences postoperative pain and effusion, ${ }^{53,54}$ cooling should begin immediately after the operation. Furthermore, cooling should avoid intraarticular hyperthermia as it has been shown that an increase in joint temperature stimulates proteolytic enzymes and cytokines and thus is harmful to the articular cartilage. ${ }^{33,34,68}$

Further important rehabilitation objectives in this first postoperative phase are the prevention of adhesions and excessive scar tissue, the restoration of full extension, and proper quadriceps activation. Physiotherapy measures therefore include patella mobilization, passive ROM exercises, and isometric quadriceps strengthening. After completion of wound healing, aquatic therapy can be used for early gait exercises.

During the transition stage (weeks 4-6 through week 12), the chondrocytes differentiate, the collagen II framework is built up, and proteoglycans form the cartilage matrix. The repair tissue has a spongy consistency and increasingly gains strength. Assuming a regular healing process, there should be good integration of the transplant and good filling of the defect after 8 weeks. ${ }^{7,15}$ Early complications including incomplete defect filling or insufficient fusion of the regenerated cartilage and healthy cartilage may occur at that stage. ${ }^{49}$ From now on, the rehabilitation protocol will be focused on the restoration of full ROM, step-wise increase in weightbearing, and gait rehabilitation. The remodeling phase (months 3-6) is characterized by an increasingly organized structure of the tissue with the formation of matrix protein crosslinks and the transplant develops an interface to bone and adjacent cartilage. ${ }^{31}$ The consistency is increasingly firm and resembles gelatin at 3 to 6 months and soft plastic after 6 months. ${ }^{31,51}$ During this phase, the focus of the rehabilitation program shifts to muscle strengthening and endurance as well as the return to functional training. The final, maturation phase lasts for up to 2 to 3 years. Matrix proteins stabilize in large aggregates and the collagen framework integrates in the subchondral bone. Rehabilitation concentrates on the restoration of full preoperative skills and the return to sports.

Besides unspecific postoperative complications including arthrofibrosis, specific complications of ACI (symptomatic graft hypertrophy, disturbed fusion, delamination and graft failure) have been described. ${ }^{49}$ The available studies addressing these complications suggest that graft failure most often is a multimodal process, contributing factors being the localization of the defect, the type of the ACI, patient age, the duration of symptoms, and prior surgical procedures as well as the defect size. ${ }^{40,49}$ Other factors (eg, smoking, high body mass index) are highly suspected to have an influence as suggested from clinical and animal studies. $^{26,35}$ Concerning the influence of rehabilitation measures on complications, the available data are sparse. A case series of 45 soccer players reported ACI failure in $13 \%$ of patients. ${ }^{45}$ These failures were attributed to graft delamination in $50 \%$, all being associated with premature weightbearing or a traumatic event. ${ }^{44}$ Patients with atraumatic failure had larger defects and longer duration of symptoms whereas no influence of rehabilitation measures was reported. It must thus be concluded that shear forces to the transplant, especially in the early stages of rehabilitation, may lead to delamination and that the knee, therefore, should initially be protected to avoid them.

\section{AVAILABLE EVIDENCE}

Compared with the increasing number of high-quality studies on clinical outcome and basic science of ACI, there is limited evidence available for rehabilitation measures after this procedure, which is based on a few randomized controlled 

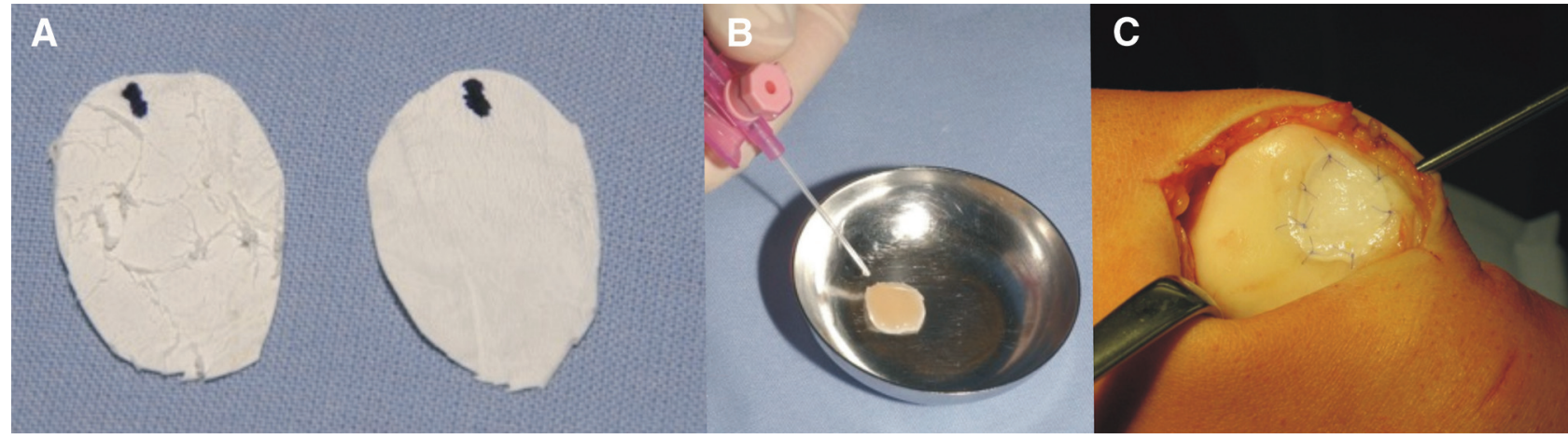

Figure 2. The ACT-CS (autologous chondrocyte transplantation-collagen membrane seeding) technique uses a porcine collagen type I/III membrane (Chondro-Gide, Geistlich, Wolhusen, Switzerland) for cell delivery. A, the rough cell-adherent side of the membrane and the smooth occlusive side. B, immediately before implantation, the chondrocytes are seeded on the rough side of the membrane. After waiting for cell adherence for $\sim 5$ minutes, the cell matrix construct is transferred into the defect so that the cell-seeded side of the membrane is directed toward the subchondral bone. C, the transplant is attached with single stitches to the adjacent cartilage using PDS (polydioxanone) 6-0 suture material in this patellar lesion after traumatic patellar dislocation.
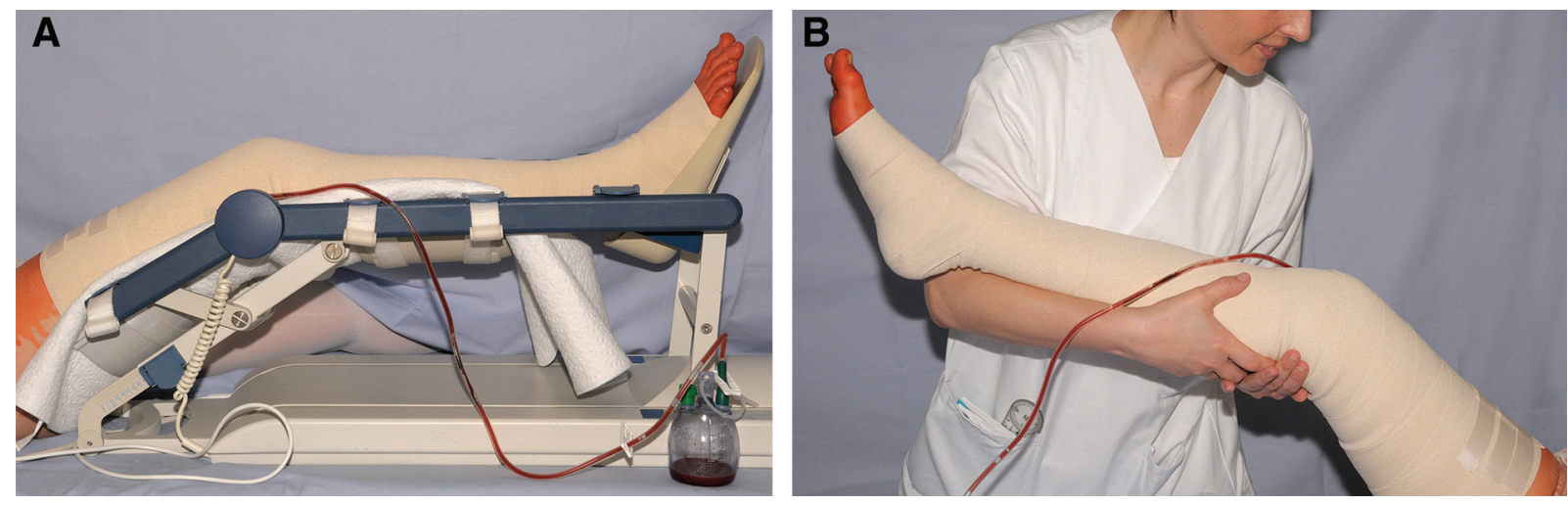

Figure 3. Early passive joint mobilization: A, continuous passive motion on the Arthromot (ORMED GmbH, Freiburg, Germany); B, manual joint mobilization.

studies. ${ }^{69}$ Therefore, the recommendations given in this paper are additionally based on the results of studies dealing with postoperative care after other joint procedures and the rehabilitation of acute injuries where available.

Cryotherapy has shown its efficacy in the reduction of pain and edema after total knee arthroplasty and anterior cruciate ligament (ACL) reconstruction. ${ }^{54}$ The scientific bases of the beneficial effect of cold therapy are the decreased tissue metabolism, a decreased inflammatory response, and a slowing of pain signal transmission. ${ }^{3,46} \mathrm{As}$ mentioned above, cryotherapy seems particularly important after ACI as it is well proven that increase in joint temperature is deleterious to articular cartilage. Commercially available cooling devices, providing a constant temperature reduction, are therefore useful as the reactive hyperemia occurring when using standard ice packs may be avoided. ${ }^{41}$

Positive effects of manual lymph drainage on pain and effusion are well documented after acute ankle sprains and after hindfoot operations, with the efficacy in sports rehabilitation being mainly attributed to resolution of enzyme serum levels associated with acute cell damage. ${ }^{24,36}$ It is assumed that a loss of patellar mobility may result in ROM restrictions and difficulties in quadriceps muscle-fiber recruitment. As soft tissue mobilization is supposed to prevent adhesions and scarring, soft tissue mobilization is widely used to prevent those complications, even without scientific proof of its effectiveness.

Compared with this limited evidence, it is well described that the controlled compression forces observed during partial weightbearing as well as the diffusion of synovial fluid achieved by passive joint mobilization are vital for the nutrition and the differentiation of the chondrocytes. ${ }^{19,67}$ Partial weightbearing must therefore be considered very important, although the amount of weightbearing is still a matter of controversial discussion. Traditionally, no weightbearing or only toe-touch weightbearing was allowed for 4 to 6 weeks in femoral lesions, followed by a step-wise increase to full weightbearing over the next 6 weeks. ${ }^{21,56}$ Now, various authors have proposed partial loading with $15 \%$ to $25 \%$ body weight for 6 weeks beginning from week 2 followed by a gradual increase to full weightbearing after 8 to 12 weeks. ${ }^{7,31,47}$ More recent 
studies even propose a gradual step-wise load increase beginning from week 3 and reaching full weightbearing after 6 to 12 weeks. ${ }^{47,58}$ In the last few years, those accelerated weightbearing protocols became justified by wellconducted clinical studies. A recent level 1 study showed a significant reduction in joint effusion with early weightbearing without negative influences on bone-marrow edema on MRI or functional outcome. ${ }^{69}$ The 2 studies by Ebert et $\mathrm{al}^{22,23}$ additionally showed that patients rehabilitated by an accelerated protocol achieved greater 6 -minute walk distances, greater daily activity levels, and a significantly better improvement in knee pain at 12 weeks as well as lower levels of gait dysfunction compared with the patients obtaining a traditional protocol. An early start of partial weightbearing therefore seems to be safe for the graft and associated with a better clinical and functional outcome. Aquatic therapy is very useful to initiate gait training as the amount of weightbearing force is reduced to approximately $25 \%$ body weight when the patient is in the water to the level of the axilla, and to $50 \%$ body weight when in the water to the level of the waist. ${ }^{32}$

It has been shown for various other knee injuries that preoperative quadriceps strength is a major predictor for postoperative joint function. ${ }^{25} \mathrm{~A}$ recent publication on isokinetic strength measurements after ACI showed significant reduction in total work on the operated leg compared with the noninjured leg at 1,2 , and 8 years after surgery. ${ }^{39}$ Similar results were found in an as-yet unpublished study by our group showing significantly lower isokinetic peak torque values at $60 \mathrm{deg} / \mathrm{s}$ and $180 \mathrm{deg} / \mathrm{s}$ on the operated leg 4 years after matrix-associated ACI. Both studies demonstrated that the deficits are more pronounced in knee extensors than in knee flexors. In our study, we furthermore found that patients treated for patellofemoral cartilage defects have greater strength deficits at 4 years than do patients treated on the femoral condyle. Considering the fact that quadriceps weakness is well associated with functional deficits of the lower extremity and that quadriceps weakness is considered a primary risk factor for knee pain, disability, and progression of joint damage, ${ }^{60,61,66}$ full restoration of quadriceps strength should be considered a main goal of rehabilitation after ACI. We therefore recommend putting particular emphasis on the development of individually adapted strength exercises at all stages of rehabilitation progress and starting isometric quadriceps strength training postoperatively as soon as possible.

It has also been previously shown that proprioception is impaired in patients with knee pain ${ }^{11}$ and various knee joint disorders including osteoarthritis, ${ }^{10}$ ACL insufficiency, ${ }^{8,9,20}$ and patellofemoral pain syndrome. ${ }^{4}$ Roberts et $\mathrm{al}^{57}$ showed that the extent of proprioceptive deficits in ACL insufficiency is correlated with the concomitant cartilage lesions. Furthermore, it has been shown that high activity levels before injury are related to better proprioception after injury and that proprioception is highly correlated to clinical outcome and patient satisfaction. ${ }^{28,57} \mathrm{As}$ there are, to our knowledge, no data on proprioception and sensorimotor control in ACI patients available, speculation remains on the equal importance of proprioceptive rehabilitation in these patients.
A recent systematic review on return to sports after different cartilage repair techniques including more than 1300 patients summarized postoperative sports participation after microfracture, autologous chondrocyte transplantation, and osteochondral transplantation. ${ }^{44}$ The authors report an overall very high return to sports rates after cartilage repair $(73 \%)$. Patients treated with ACI had the highest long-term durability of continued sports participation (96\%). It was also shown that ACI patients had a significantly later return to sports (mean, $18 \pm 4$ months; range, 12-36 months) compared with patients who underwent the other surgical procedures (mean $7.5 \pm 2$ months). Interestingly, the time to return to sports was significantly shorter in competing compared with recreational athletes and the overall return rates were significantly higher in competing athletes $(71 \%-86 \%$ vs $19 \%$ $29 \%$ ). Furthermore, better filling of the defect was observed in competitive athletes. ${ }^{12}$ Better compliance in the rehabilitation process, high motivation, and better access to rehabilitation facilities may be contributing to this. Therefore, intensive and consequent realization of the rehabilitation process can be considered highly important for the long-term outcome. On the other hand, traumatic delamination from graft hypertrophy is responsible for up to $50 \%$ of failures after ACI in high-impact athletes, ${ }^{44,45}$ leading to the conclusion that caution is warranted when returning to high-impact sports.

In addition to this, Kreuz et $\mathrm{al}^{38}$ demonstrated that preinjury activity levels and sports participation in the later phases of rehabilitation are important factors in the improvement of long-term results after ACI of the knee. They showed a high correlation between patients' sports activity level and their clinical scores at follow-up. Regarding the whole study period and the statistical evaluation, they concluded that physical training should be carried out for at least 3 years after surgery.

\section{PROPOSED REHABILITATION PROTOCOL}

Taking all the above-mentioned information into account, the following rehabilitation protocol was introduced for patients after ACI for isolated cartilage defects of the knee joint (Table 1). Although we are aware that the presented protocol lacks high-level scientific evidence, it has proven to be clinically efficient in many patients who were followed up after ACI for cartilage defects of the knee. ${ }^{37,48,64}$ Clinicians and physiotherapists have to be aware that all rehabilitation protocols after ACI should be considered guidelines rather than fixed protocols and need to be adapted individually for every patient. In our opinion, the rehabilitation process of ACI patients-even for an ideal "standard patient"-is one of the most individualized rehabilitation processes in orthopaedic surgery, where intensive cooperation among surgeon, physiotherapist, athletic trainer, and patient is of crucial importance. The patient should be well instructed and affiliated with a rehabilitation center.

According to the biomechanical differences and the different cartilage loading of the patellofemoral and 
TABLE 1

Phases of the Proposed Rehabilitation Protocol for Tibiofemoral ACI ${ }^{a}$

\begin{tabular}{|c|c|c|c|}
\hline & Weightbearing, Mobilization, ROM & Measures & Goals \\
\hline \multirow[t]{4}{*}{ Day 1} & Brace in full extension & Cryotherapy (24 h) & Resorption of joint effusion \\
\hline & to toilet allowed & Thrombosis prophylaxis exercises (ankle & \\
\hline & Partial WB (15 kg, crutches) & plantar flexion and dorsiflexion) & \\
\hline & for 6 weeks & Isometric quadriceps training & \\
\hline & Removal of suction drain and & hour if tolerated) & Neuromuscular activation \\
\hline & $0^{\circ}$ brace & Isometric quadriceps training: $15 \mathrm{sec}$, no. of & \\
\hline & $\begin{array}{l}\text { Partial WB (15 kg, crutches) } \\
\text { for } 6 \text { weeks }\end{array}$ & $\begin{array}{l}\text { repetitions adapted to discomfort and } \\
\text { edema (every hour if tolerated) }\end{array}$ & \\
\hline & ROM: free $/ 0^{\circ} / 90^{\circ}$ & Gait training & \\
\hline & & CPM $0^{\circ}-90^{\circ} 4-8 \mathrm{~h} /$ day for 6 weeks & \\
\hline \multirow[t]{2}{*}{ Weeks 4-6 } & Partial WB (15 kg, crutches) & Closed kinetic chain exercises & \\
\hline & ROM: free $/ 0^{\circ} / 90^{\circ}$ & Cycling ergometer & \\
\hline \multicolumn{4}{|c|}{ Transition stage } \\
\hline \multirow[t]{5}{*}{ From week 7} & Step-wise increase to full WB & Full active flexion & Normal gait pattern \\
\hline & Full ROM & Closed kinetic chain exercises & Full ROM \\
\hline & & Cycling ergometry & Enhancement of muscular \\
\hline & & Sensorimotor training with increased loading & strength and endurance \\
\hline & & $\begin{array}{l}\text { Core stability exercises, coordination } \\
\text { exercises }\end{array}$ & capacities \\
\hline \multirow[t]{3}{*}{ From week 9} & Full WB & Intensive hypertrophy training including & Maximum knee flexion \\
\hline & Free ROM & OKC exercises and weight lifting & Stable gait pattern \\
\hline & & Stability exercise of increased load & Restoration of neuromuscular \\
\hline
\end{tabular}

${ }^{a} \mathrm{ACI}$, autologous chondrocyte implantation; CPM, continuous passive motion; OKC, open kinetic chain; PNF, proprioceptive neuromuscular facilitation; ROM, range of motion; WB, weightbearing.

tibiofemoral joint, different rehabilitation schemes for patellofemoral ACI (PF-ACI) and for tibiofemoral ACI (TF-ACI) are accepted by various authors. ${ }^{14,31,42}$ The selection of the rehabilitation protocol is based on defect characteristics (uncontained or contained), the site, and the dimension of the ACI, which, of course, is determined intraoperatively and defined by the operating surgeon.

\section{Preoperative Phase}

As mentioned earlier, preoperative quadriceps strength, proprioception, and sensorimotor control are important factors for postoperative functional ability in patients with cartilage defects. Therefore, the patients are instructed to perform preoperative quadriceps strength training and proprioceptive exercises at least 3 times a week. Additionally, patient education about the surgical procedure and the rehabilitation process is highly important during this phase. Ideally, preoperative strength training should be performed over 3 months. The minimum time required is 4 to 6 weeks to at least induce an increase in maximal contractile muscle force attributable to neuronal adaptations. ${ }^{1}$ The time needed for cultivation of the chondrocytes after biopsy can be used perfectly to enhance patient muscle strength. Sedentary patients or individuals to be considered novice to strength training regimens should train 2 to 3 times a week. A single training unit should include free-weight lifting and machine exercises performed for 1 to 3 sets per exercise (2-3 minutes rest between sets) at $60 \%$ to $70 \%$ of the individual's 1-repetition maximum (1 RM). Unilateral and bilateral single- and multiple-joint exercises can be included. Multiple-joint exercises should be preferred because of their functional relevance in activities of daily living. ${ }^{5}$

If it is possible to extend the preoperative training phase to 3 months, structural changes in the muscle architecture including muscle fiber hypertrophy can be expected. ${ }^{2}$ To 
achieve progress in individuals with low sporting activity levels toward intermediate or athletic populations, extending the number of training units to 4 to 6 per week is required. Concentric, eccentric, and isometric muscle exercises should be included in the training routine to develop all muscle contraction modes. Guidelines recommend triggering specific muscle hypertrophy responses in the advanced training state by loading at a range of $70 \%$ to $100 \%$ of $1 \mathrm{RM}$. It is recommended to perform 1 to 12 repetitions per set for 3 to 6 sets, where the majority of training is dedicated to 6 to 12 repetitions and less to 1 to 6 repetitions.

\section{Early Phase (Weeks 1-6)}

The main goals during the first 6 weeks of the rehabilitation process are to reduce intra-articular effusion, restore full ROM, maintain patellar mobility, and avoid shear forces on the transplantation site to allow graft integration. The surgeon will decide about restricting the ROM and limitations of joint loading intraoperatively depending on the size and the location of the lesion. Usually, the ROM restriction is $30^{\circ}$ for patellofemoral transplants and $90^{\circ}$ for femoral condyle transplants. This might be extended (eg, in the rare cases of inferior patella pole lesions where the restriction might initially be only $15^{\circ}$ of flexion).

At the end of the operation, a suction drain is placed in the contralateral suprapatellar recessus to not harm the transplant, and the operated leg is wrapped with an elastic bandage from the forefoot to the upper thigh. A knee immobilization brace locked in full extension (Medi Jeans, Medi, Bayreuth, Germany [Figure 4]) is applied to prevent shear forces to the transplant and a dislocation of the suction drain when the patient is weaned from the anesthesia, is sleeping, or is mobilized to the bathroom for the first time where he or she might inadvertently flex the knee. Additionally, an anatomically formed cryocuff device that allows for continuous cooling at $15^{\circ} \mathrm{C}$ (Hilotherm, Hilotherm GmbH, Ludwigsburg, Germany [Figure 4]) is placed into the brace promptly after surgery. With the help of this system, the temperature applied to the knee joint is kept constant at $15^{\circ}$ for the first postoperative days, avoiding the reactive hyperemia that is regularly seen in classic ice therapy. Additionally, it provides pain relief and reduction of postoperative swelling. Postoperatively, bed rest is recommended for the first 12 to 24 hours, mainly to avoid massive swelling and to provide a maximum of safety during the period in which the chondrocytes adhere to the subchondral bone plate. The postoperative bandage is usually left on for 36 to 48 hours. Whenever the patient is in control of his or her knee, the brace can be opened or removed so that the knee can be positioned as comfortable, respecting the given ROM limits, of course. As early passive joint mobilization is crucial for restoring full ROM and, as mentioned before, for the nutrition of the cartilage, passive joint mobilization is started as early as 12 hours after surgery if tolerated (Figure 3). After removal of the suction drain, usually on day 2, passive joint mobilization and manual mobilization of the patella is increased. Continuous passive motion (Arthromot device) is recommended for 6 to 8 hours per day, starting from $0^{\circ}$ to $40^{\circ}$ on day 1 ,

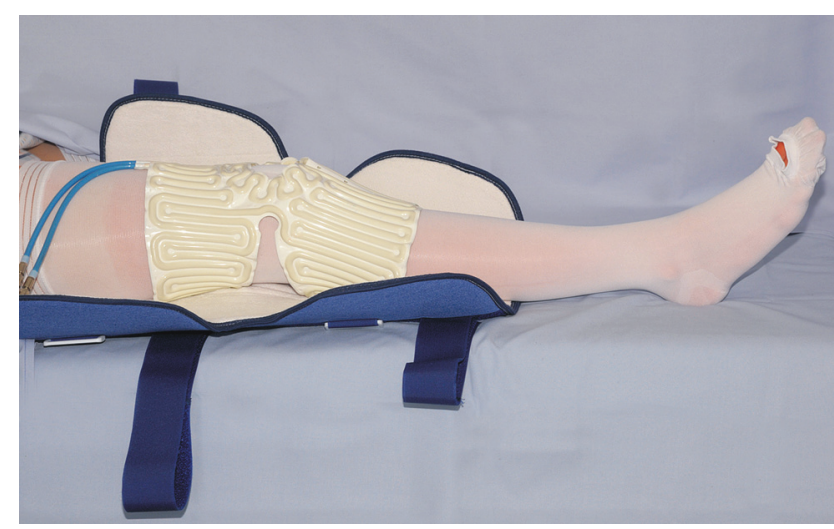

Figure 4. Patient equipped with our standard knee extension brace (Medi Jeans) and a commercial cooling device (Hilotherm) that allows for continuous cooling at $15^{\circ} \mathrm{C}$, so that the periarticular temperature remains constant and reactive hyperemia may be avoided.

progressing to $0^{\circ}$ to $60^{\circ}$ in tibiofemoral ACI (TF-ACI) over the following days as tolerated (Figure 3A). Continuous passive motion is continued at home after discharge from the hospital for 6 weeks postoperatively whereby the ROM limit is extended to $60^{\circ}$ in week 3 in PF-ACI and to $90^{\circ}$ in week 5 in both groups. Mobilization on crutches is instructed by a well-trained physical therapist on day 1 (Figure 5). With respect to the maintenance of a normal gait pattern, partial weightbearing with $20 \%$ to $25 \%$ body weight is allowed immediately. Patients with patellofemoral lesions are encouraged to carry out full weightbearing in full extension of the knee as soon as there is no more effusion. Active dorsiflexion and plantar flexion exercises of the ankle are also instructed by the therapist and should be done as often as possible to prevent thrombosis and encourage circulation. Manual lymph drainage is performed once daily (Figure 6). Furthermore, patients with TF-ACI are asked to perform isometric quadriceps exercises to reduce joint effusion, while we recommend being more restrictive with quadriceps exercises during the first few days after ACI in patellofemoral lesions. With the knee joint fully extended and dorsiflexed ankle, the leg is lifted $10 \mathrm{~cm}$ and held in this position for $15 \mathrm{sec}-$ onds (Figure 7). After gently putting the calf back down, the quadriceps muscle is relaxed for 20 seconds and the cycle starts again. Patients are asked to perform this isometric exercise 10 times $(10 \times 15$ seconds, 20-second pause) per hour during daytime. To avoid muscle dysbalance, we recommend isometric exercises of the antagonists (hamstrings) by pressing the dorsiflexed ankle down on the mattress. During the following days, active self-assisted ROM exercises (using the contralateral leg), proprioceptive neuromuscular facilitation (Figure 8), and cross-education exercises (resistance training of contralateral leg) are introduced. Before discharge from the hospital, a brace limiting the knee joint range of motion to $90^{\circ}$ of flexion in TF-ACI and to $30^{\circ}$ of flexion in PF-ACI (Collamed, Medi [Figure 9]) is fitted. The ROM limit is extended to $60^{\circ} 2$ weeks postoperatively and to $90^{\circ} 4$ weeks 


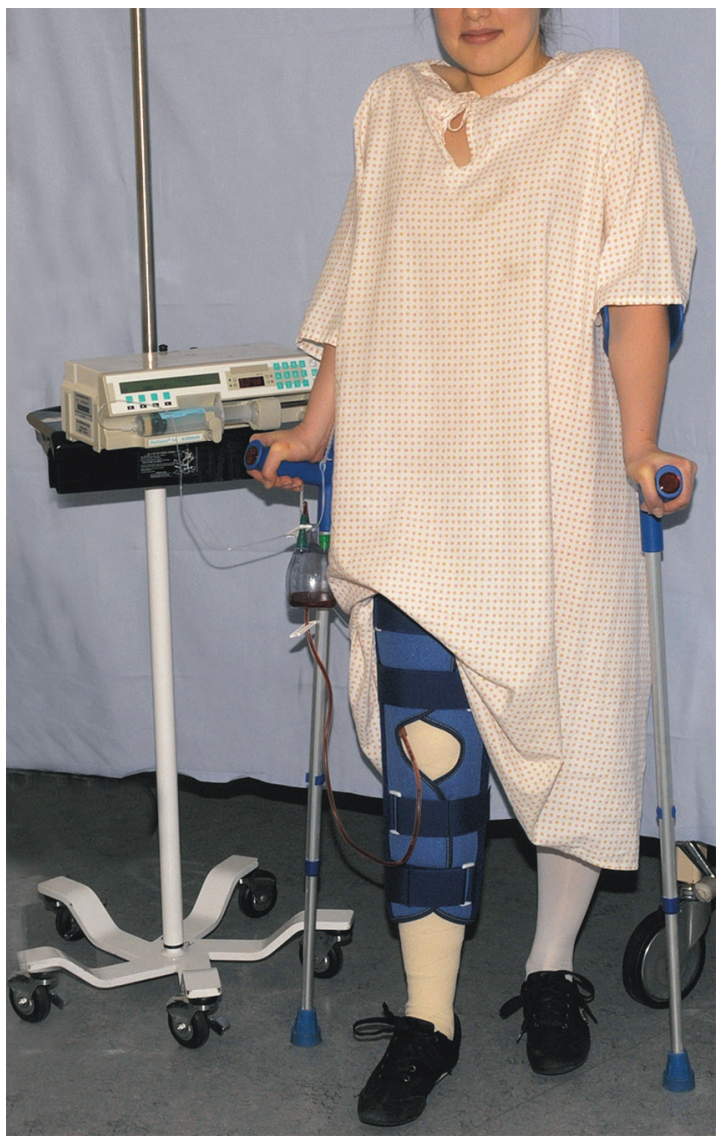

Figure 5. Mobilization on crutches is instructed on day 1.

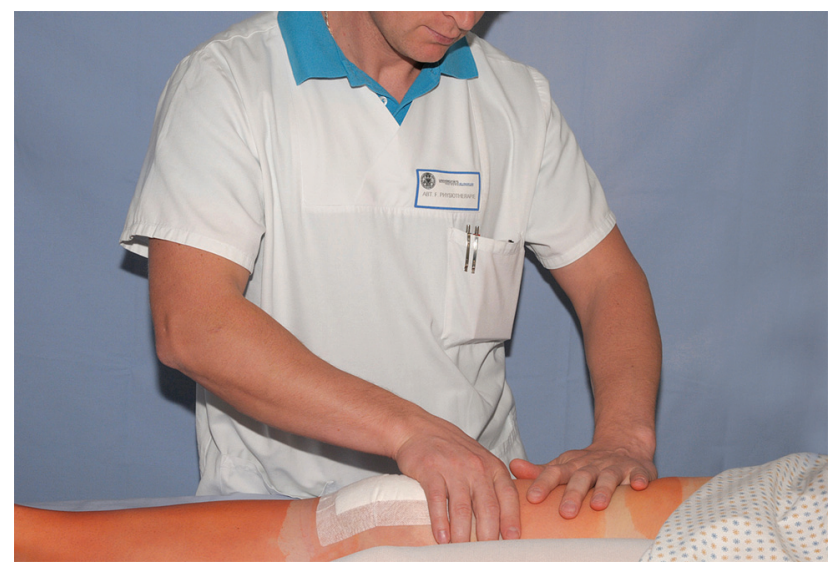

Figure 6. Manual lymph drainage on day 2.

postoperatively in PF-ACI. In both groups the brace is removed at the end of week 6 . Full mobilization of the patient under partial weightbearing (20\%-25\% body weight), including climbing stairs, has to be achieved before discharge from the hospital (Figure 10). Usually patients are hospitalized for 5 days. After the completion of wound healing, patients proceed to aquatic therapy (unloaded gait and strength training and training of aerobic capacity).

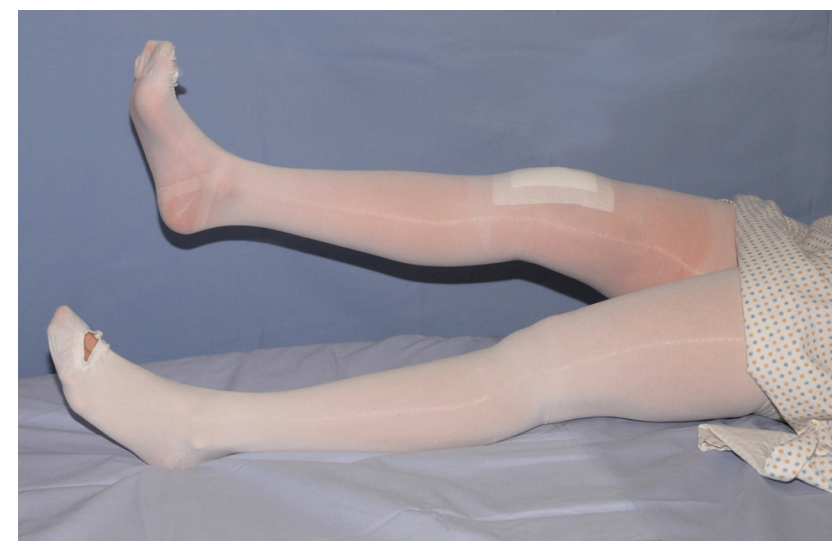

Figure 7. Isometric quadriceps exercises to reduce joint effusion.

In the following weeks, closed kinetic chain exercises with partial weightbearing as well as ergometer and treadmill training (Figure 11) to maintain or regain cardiorespiratory fitness $(3 \times 45 \mathrm{~min} / \mathrm{wk})$ are successively introduced depending on the subjective report of the patient's symptoms and objective clinical signs such as effusion and crepitation. The main objective in the first rehabilitation phase should be the restoration of joint balance. The absence of local hyperthermia and swelling as well as full knee extension are criteria for progression to the next phase.

\section{Weeks 6 to 12}

Rehabilitation in the transition stage is focused on the restoration of full ROM and the step-wise increase in joint loading. Further objectives are the enhancement of endurance capacity and the restoration of a normal gait pattern. Strength and proprioceptive performance capacities are addressed by closed kinetic chain exercises and sensorimotor training on unstable ground (Figure 12). In the beginning, ROM is restricted to $0^{\circ}$ to $30^{\circ}$ in PF-ACI and $0^{\circ}$ to $60^{\circ}$ in TF-ACI for strength training. Patients are more and more directed toward increased active ROM exercises and are weaned from the brace. Closed kinetic chain exercises are started with both legs and progressed to partialloaded single-leg exercises. Cycling is started about 4 weeks postoperatively. An intensive gait rehabilitation program to avoid asymmetrical gait patterns supports the transition to full weightbearing. Sensorimotor training is progressed by incremental coordinative exercises starting on even ground and later on unstable ground (eg, Airex Balance Board [Figure 12], Thera-Band Stability Trainer, Thera-Band GmbH, Hygenic Corporation, Akron, Ohio). Criteria for the transition to the next phase are full ROM, full weightbearing, and an almost normal gait pattern.

\section{Weeks 12 to 26}

The phase from week 12 to week 26 is characterized by strength training, maximum sensorimotor stimulation, and the return to sports. Endurance training should be performed for more than 60 minutes at least 3 times per week. ${ }^{52}$ Besides indoor and outdoor cycling and walking on 


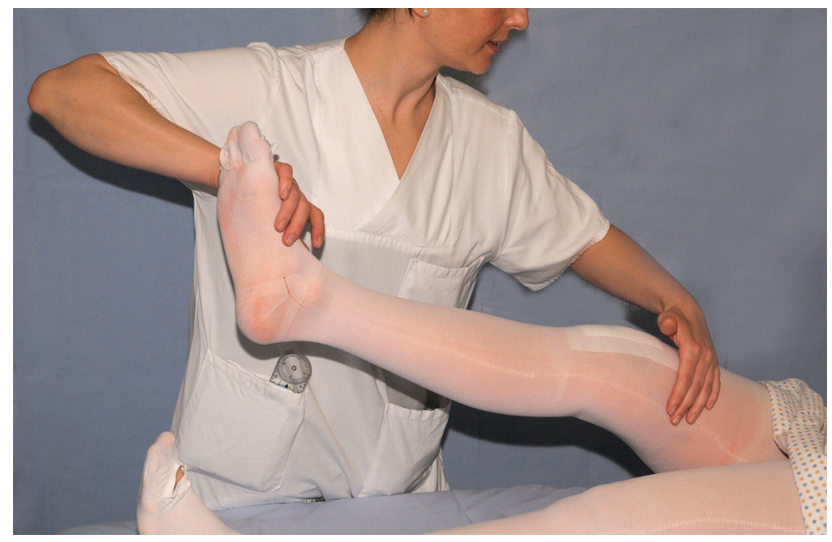

Figure 8. Proprioceptive neuromuscular facilitation: leg pattern.

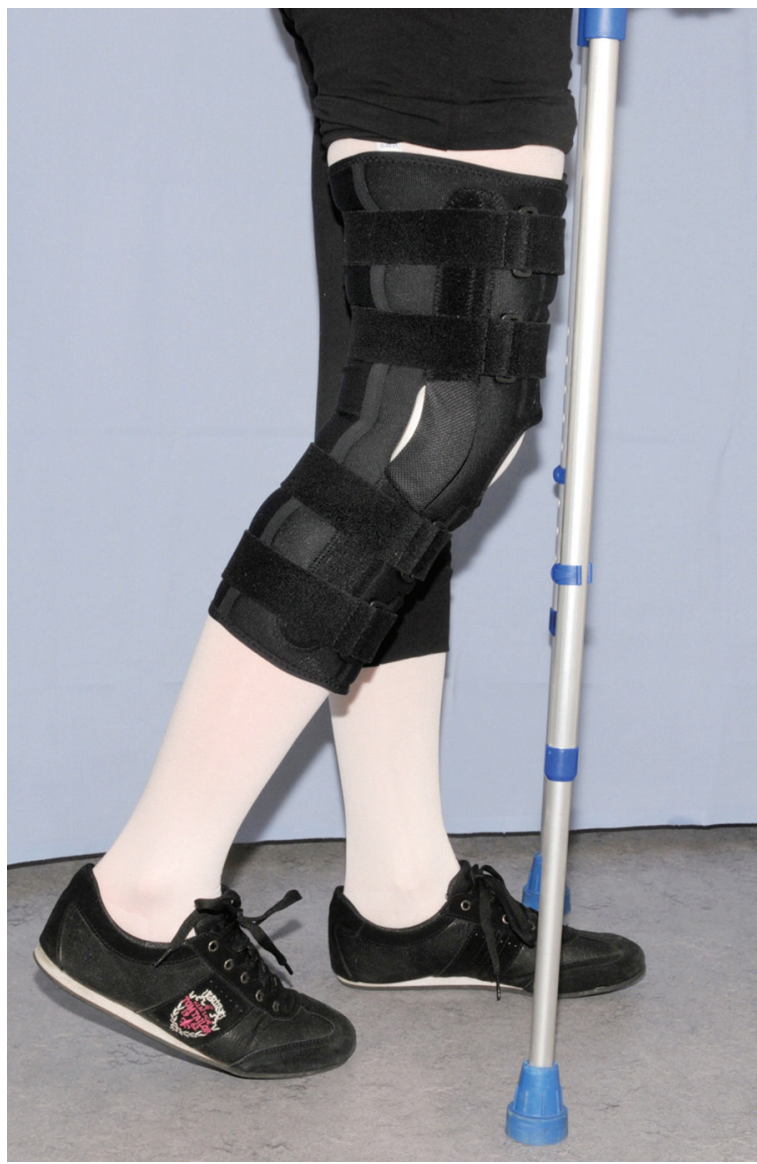

Figure 9. Flexible knee brace limiting the knee joint range of motion to $90^{\circ}$ flexion in tibiofemoral autologous chondrocyte implantation $(\mathrm{ACl})$ and $30^{\circ}$ flexion in patellofemoral $\mathrm{ACl}$ (Medi Collamed).

the treadmill or Nordic walking, rowing ergometers, elliptical cross trainers, or steppers may be used. Full ROM (open kinetic chain [OKC]) exercises are performed with an increased load. Proprioceptive exercises focus on the full restoration of neuromuscular control by increasingly demanding

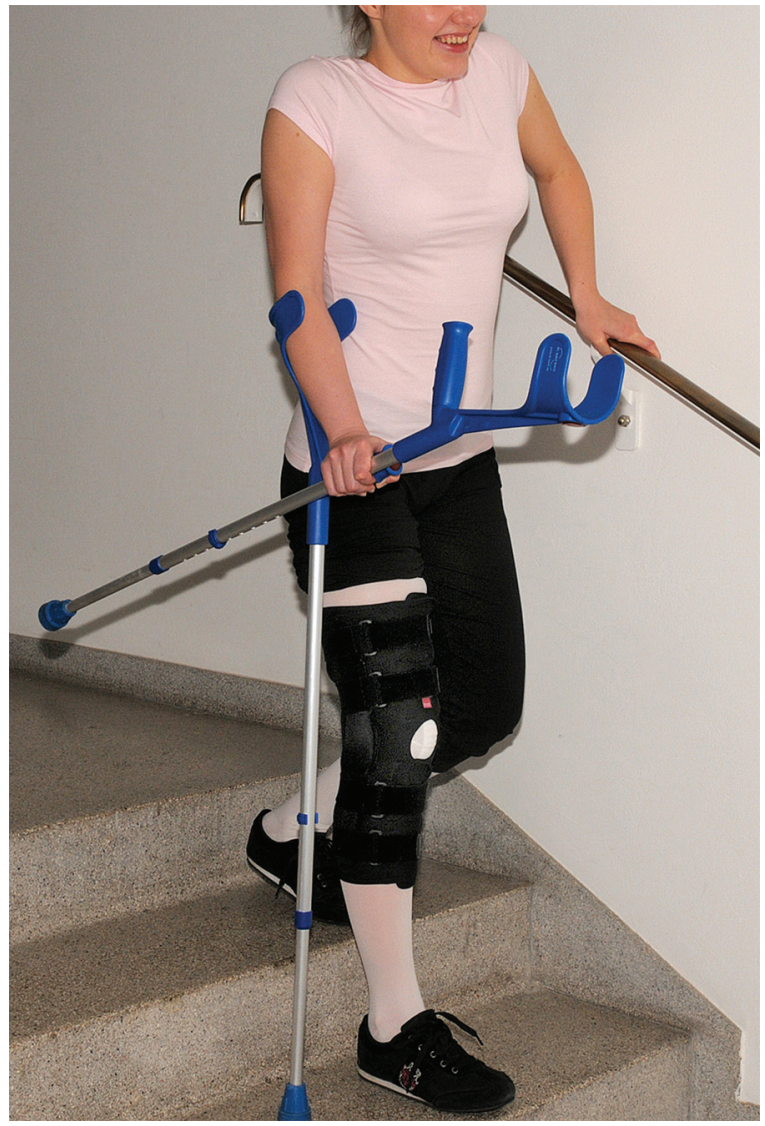

Figure 10. Full mobilization of the patient under partial weightbearing (20\%-25\% body weight) including climbing stairs has to be achieved before discharge from the hospital.

functional skills using balance boards, gymnastic balls, stability trainers, rocker and wobble boards, exercise bands, and so forth. Six months postoperatively, light jogging and unidirectional sports-specific agility training may be initiated.

\section{After Week 26}

A step-wise return to sports is allowed depending on the persisting side-to-side differences of the limbs and clinical symptoms. Criteria for unrestricted sports performance include being completely pain-free and having normal findings in the clinical examination of the knee joint as well as an almost complete return of strength and sensorimotor control, which should be verified before returning to sports. Analogous to the rehabilitation after ACL reconstruction, peak torque higher than $80 \%$ of the contralateral leg and an almost normal proprioception are considered major prerequisites for the return to on-field physical activity. Proprioceptive capacities can be measured functionally by the assessment of postural control (Posturomed, Haider Bioswing, Pullenreuth, Germany). Concerning strength performance, the required minimum strength of $80 \%$ of the noninjured side may best be measured using an isokinetic device (eg, Contrex MJ, Dübendorf, Switzerland; Biodex System 4, Biodex Medical Systems, Shirley, New 


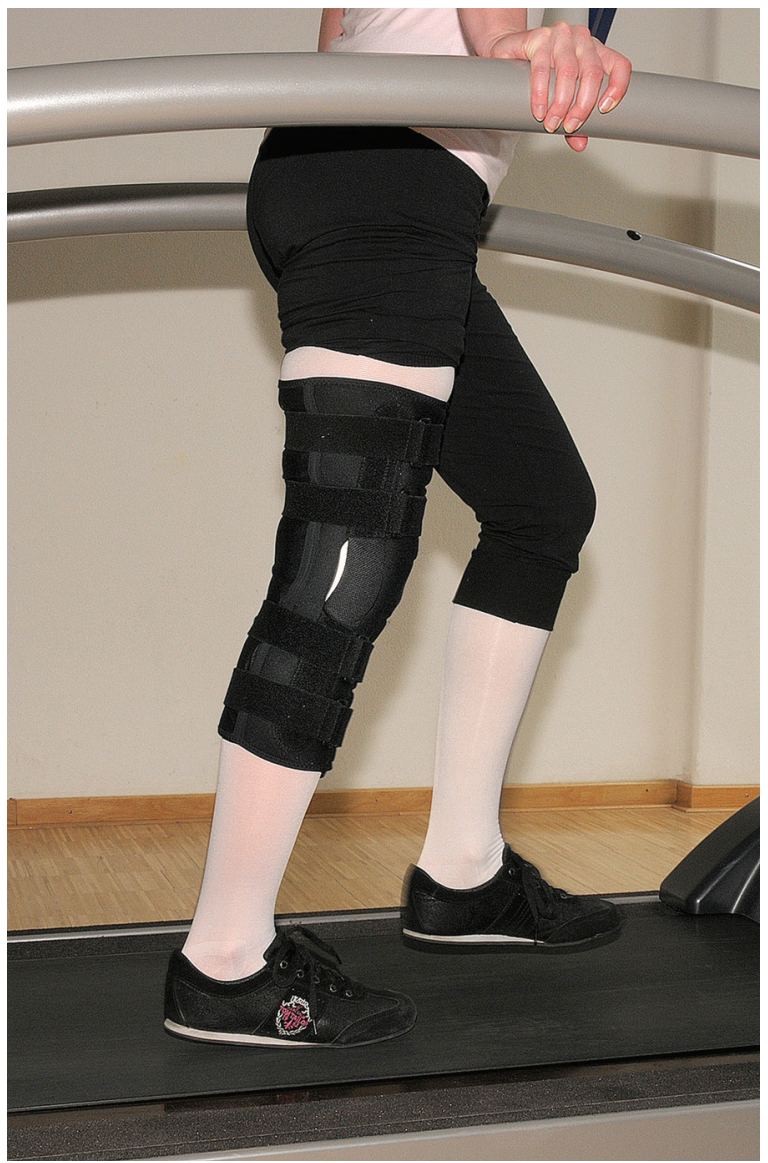

Figure 11. Early start of partial weightbearing treadmill training.

York; Cybex, CSMi, Stoughton, Massachusetts). Patients are finally encouraged to maintain participation in sports for at least 2 years after surgery. ${ }^{38}$ It seems obvious that a healthy lifestyle contributes to a good long-term outcome of ACI. It is therefore recommended that patients ideally follow general guidelines as outlined by the American College of Sports Medicine (ACSM) ${ }^{52}$ long term after surgery and not only for the scientifically proven 2 -year period. ${ }^{38}$ Cardiorespiratory fitness should be trained 3 to 5 times per week with cyclic movements involving big muscle groups (walking, running, cycling, cross-country skiing, and aqua fitness) at $55 \%$ to $90 \%$ of the individual maximal heart rate. Every training unit should last at least 20 minutes and can be extended up to 60 minutes. Besides cardiorespiratory fitness, muscular strength is the other key component that should be trained 2 to 3 times per week with 8 to 10 exercises involving functional exercises using the full ROM possible. Training has to be split up into 2 to 3 sets with 6 to 8 or 8 to 12 repetitions of $1 \mathrm{RM}^{52}$

\section{PERSPECTIVE}

Our goal for all future patients undergoing ACI is a preoperative standard evaluation by a physical therapist. Furthermore, strength testing should be implemented to evaluate basic presurgical strength capacities and survey

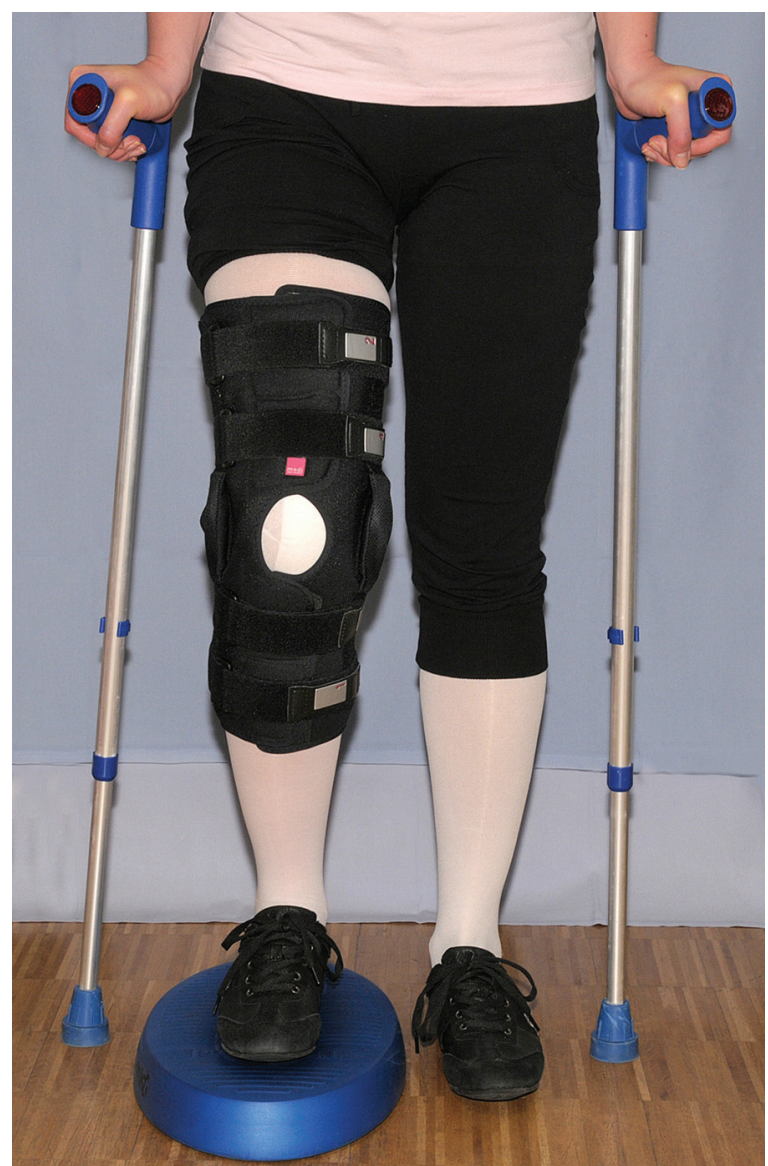

Figure 12. Sensorimotor training: coordinative exercises on unstable ground (Airex Balance Board, Gaugler und Lutz, Aalen, Germany)

the rehabilitation progress. As there is a lack of scientific evidence concerning the relationship between preoperative strength capacities and postoperative outcome in ACI patients, preoperative strength measurements are also of high interest for further investigations. These data may affect the decision on the optimal time and preconditioning for surgical interventions. Furthermore, criteria for progression to the next rehabilitation phase should be better defined. We encourage high-quality studies on the topic of rehabilitation after cartilage repair.

Increasing scientific evidence will lead to further improvement of the rehabilitation protocols for patients who undergo cartilage repair in the future.

\section{ACKNOWLEDGMENT}

The authors acknowledge the contribution of a professional photographer, Mr Wehrle, as well as physiotherapist Sandra Schmiedecke and masseur Victor Lehr for their help in taking representative photographs of a standard patient. Our acknowledgement is also extended to $\mathrm{Mr}$ Duncan Cummins for language support. 
An online CME course associated with this article is available for 1 AMA PRA Category 1 Credit $^{\mathrm{TM}}$ at http:// ajsm-cme.sagepub.com. In accordance with the standards of the Accreditation Council for Continuing Medical Education (ACCME), it is the policy of The American Orthopaedic Society for Sports Medicine that authors, editors, and planners disclose to the learners all financial relationships during the past 12 months with any commercial interest (A 'commercial interest' is any entity producing, marketing, re-selling, or distributing health care goods or services consumed by, or used on, patients). Any and all disclosures are provided in the online journal CME area which is provided to all participants before they actually take the CME activity. In accordance with AOSSM policy, authors, editors, and planners' participation in this educational activity will be predicated upon timely submission and review of AOSSM disclosure. Noncompliance will result in an author/editor or planner to be stricken from participating in this CME activity.

\section{REFERENCES}

1. Aagaard $P$. Training-induced changes in neural function. Exerc Sport Sci Rev. 2003;31(2):61-67.

2. Aagaard P, Andersen JL, Dyhre-Poulsen $P$, et al. A mechanism for increased contractile strength of human pennate muscle in response to strength training: changes in muscle architecture. $J$ Physiol. 2001;534(Pt 2):613-623.

3. Abramson DI, Chu LS, Tuck S Jr, Lee SW, Richardson G, Levin M. Effect of tissue temperatures and blood flow on motor nerve conduction velocity. JAMA. 1966;198(10):1082-1088.

4. Akseki D, Akkaya G, Erduran M, Pinar H. Proprioception of the knee joint in patellofemoral pain syndrome [in Turkish]. Acta Orthop Traumatol Turc. 2008;42(5):316-321.

5. American College of Sports Medicine position stand: progression models in resistance training for healthy adults. Med Sci Sports Exerc. 2009;41(3):687-708.

6. Andereya S, Maus U, Gavenis K, et al. First clinical experiences with a novel 3D-collagen gel (CaReS) for the treatment of focal cartilage defects in the knee [in German]. Z Orthop Ihre Grenzgeb. 2006;144(3):272-280.

7. Bailey A, Goodstone N, Roberts S, et al. Rehabilitation after Oswestry autologous chondrocyte implantation: the OsCell Protocol. J Sport Rehabil. 2003;12(2):104-118.

8. Barrack RL, Skinner HB, Buckley SL. Proprioception in the anterior cruciate deficient knee. Am J Sports Med. 1989;17(1):1-6.

9. Barrett DS. Proprioception and function after anterior cruciate reconstruction. J Bone Joint Surg Br. 1991;73(5):833-837.

10. Barrett DS, Cobb AG, Bentley G. Joint proprioception in normal, osteoarthritic and replaced knees. J Bone Joint Surg Br. 1991;73(1):53-56.

11. Bennell K, Hinman R. Exercise as a treatment for osteoarthritis. Curr Opin Rheumatol. 2005;17(5):634-640.

12. Blevins FT, Steadman JR, Rodrigo JJ, Silliman J. Treatment of articular cartilage defects in athletes: an analysis of functional outcome and lesion appearance. Orthopedics. 1998;21(7):761-767; discussion 767-768.

13. Breinan HA, Minas T, Hsu HP, Nehrer S, Sledge CB, Spector M. Effect of cultured autologous chondrocytes on repair of chondral defects in a canine model. J Bone Joint Surg Am. 1997;79(10):1439-1451.

14. Brittberg M. Autologous chondrocyte implantation-technique and long-term follow-up. Injury. 2008;39(Suppl 1):S40-49.

15. Brittberg M. Cell carriers as the next generation of cell therapy for cartilage repair: a review of the matrix-induced autologous chondrocyte implantation procedure. Am J Sports Med. 2010;38:1259-1271.
16. Brittberg M, Lindahl A, Nilsson A, Ohlsson C, Isaksson O, Peterson L. Treatment of deep cartilage defects in the knee with autologous chondrocyte transplantation. N Engl J Med. 1994;331(14):889-895.

17. Brittberg M, Tallheden T, Sjogren-Jansson B, Lindahl A, Peterson L. Autologous chondrocytes used for articular cartilage repair: an update. Clin Orthop Relat Res. 2001;391(Suppl):S337-S348.

18. Buckwalter JA, Mankin HJ. Articular cartilage: degeneration and osteoarthritis, repair, regeneration, and transplantation. Instr Course Lect. 1998;47:487-504.

19. Buckwalter JA, Mow VC, Ratcliffe A. Restoration of injured or degenerated articular cartilage. J Am Acad Orthop Surg. 1994;2(4):192-201.

20. Corrigan JP, Cashman WF, Brady MP. Proprioception in the cruciate deficient knee. J Bone Joint Surg Br. 1992;74(2):247-250.

21. Della Villa S, Kon E, Filardo G, et al. Does intensive rehabilitation permit early return to sport without compromising the clinical outcome after arthroscopic autologous chondrocyte implantation in highly competitive athletes? Am J Sports Med. 2010;38(1):68-77.

22. Ebert JR, Lloyd DG, Smith A, Ackland T, Wood DJ. The association between external-ground-reaction force and knee-joint kinetics during partial- and full-weight-bearing gait. Clin Biomech (Bristol, Avon). 2010;25:359-364.

23. Ebert JR, Robertson WB, Lloyd DG, Zheng MH, Wood DJ, Ackland T. Traditional vs accelerated approaches to post-operative rehabilitation following matrix-induced autologous chondrocyte implantation (MACl): comparison of clinical, biomechanical and radiographic outcomes. Osteoarthritis Cartilage. 2008;16(10):1131-1140.

24. Eisenhart AW, Gaeta TJ, Yens DP. Osteopathic manipulative treatment in the emergency department for patients with acute ankle sprains. J Am Osteopath Assoc. 2003;103:417-421.

25. Eitzen I, Holm I, Risberg MA. Preoperative quadriceps strength is a significant predictor of knee function two years after anterior cruciate ligament reconstruction. Br J Sports Med. 2009;43(5):371-376.

26. El-Zawawy HB, Gill CS, Wright RW, et al. Smoking delays chondrogenesis in a mouse model of closed tibial fracture healing. $J$ Orthop Res. 2006;24:2150-2158.

27. Erggelet C, Kreuz PC, Mrosek EH, et al. Autologous chondrocyte implantation versus $\mathrm{ACl}$ using 3D-bioresorbable graft for the treatment of large full-thickness cartilage lesions of the knee. Arch Orthop Trauma Surg. 2010;130:957-964.

28. Fremerey RW, Lobenhoffer P, Zeichen J, Skutek M, Bosch U, Tscherne $\mathrm{H}$. Proprioception after rehabilitation and reconstruction in knees with deficiency of the anterior cruciate ligament: a prospective, longitudinal study. J Bone Joint Surg Br. 2000;82(6):801-806.

29. Gikas PD, Bayliss L, Bentley G, Briggs TW. An overview of autologous chondrocyte implantation. J Bone Joint Surg Br. 2009;91(8):997-1006.

30. Gomoll AH, Probst C, Farr J, Cole BJ, Minas T. Use of a type I/III bilayer collagen membrane decreases reoperation rates for symptomatic hypertrophy after autologous chondrocyte implantation. Am J Sports Med. 2009;37(Suppl 1):20S-23S.

31. Hambly K, Bobic V, Wondrasch B, Van Assche D, Marlovits S. Autologous chondrocyte implantation postoperative care and rehabilitation: science and practice. Am J Sports Med. 2006;34(6):1020-1038.

32. Harrison RA, Hillman M, Bulstrode S. Loading of the lower limb when walking partially immersed: implications for clinical practice. Physiotherapy. 1992;78:164-166.

33. Horstman CL, McLaughlin RM. The use of radiofrequency energy during arthroscopic surgery and its effects on intraarticular tissues. Vet Comp Orthop Traumatol. 2006;19(2):65-71.

34. Horvath SM, Hollander JL. Intra-articular temperature as a measure of joint reaction. J Clin Invest. 1949;28(3):469-473.

35. Jaiswal PK, Macmull S, Bentley G, Carrington RW, Skinner JA, Briggs TW. Does smoking influence outcome after autologous chondrocyte implantation? A case-controlled study. J Bone Joint Surg Br. 2009;91(12):1575-1578.

36. Kessler T, de Bruin E, Brunner F, Vienne P, Kissling R. Effect of manual lymph drainage after hindfoot operations. Physiother Res Int. 2003;8(2):101-110.

37. Kreuz PC, Muller S, Ossendorf C, Kaps C, Erggelet C. Treatment of focal degenerative cartilage defects with polymer-based autologous 
chondrocyte grafts: four-year clinical results. Arthritis Res Ther. 2009;11(2):R33.

38. Kreuz PC, Steinwachs M, Erggelet C, et al. Importance of sports in cartilage regeneration after autologous chondrocyte implantation: a prospective study with a 3-year follow-up. Am J Sports Med. 2007;35(8):1261-1268.

39. Loken S, Ludvigsen TC, Hoysveen T, Holm I, Engebretsen L, Reinholt FP. Autologous chondrocyte implantation to repair knee cartilage injury: ultrastructural evaluation at 2 years and long-term follow-up including muscle strength measurements. Knee Surg Sports Traumatol Arthrosc. 2009;17(11):1278-1288.

40. Marlovits S, Zeller P, Singer P, Resinger C, Vecsei V. Cartilage repair: generations of autologous chondrocyte transplantation. Eur $\mathrm{J}$ Radiol. 2006;57(1):24-31.

41. Martin SS, Spindler KP, Tarter JW, Detwiler K, Petersen HA. Cryotherapy: an effective modality for decreasing intraarticular temperature after knee arthroscopy. Am J Sports Med. 2001;29(3):288291.

42. McGinty G, Irrgang JJ, Pezzullo D. Biomechanical considerations for rehabilitation of the knee. Clin Biomech (Bristol, Avon). 2000; 15(3):160-166.

43. Minas T. Chondrocyte implantation in the repair of chondral lesions of the knee: economics and quality of life. Am J Orthop. 1998;27(11): 739-744.

44. Mithoefer K, Hambly K, Della Villa S, Silvers H, Mandelbaum BR. Return to sports participation after articular cartilage repair in the knee: scientific evidence. Am J Sports Med. 2009;37(Suppl 1):167S-176S.

45. Mithofer K, Peterson L, Mandelbaum BR, Minas T. Articular cartilage repair in soccer players with autologous chondrocyte transplantation: functional outcome and return to competition. Am J Sports Med. 2005;33(11):1639-1646.

46. Morsi E. Continuous-flow cold therapy after total knee arthroplasty. $J$ Arthroplasty. 2002;17(6):718-722.

47. Nho SJ, Pensak MJ, Seigerman DA, Cole BJ. Rehabilitation after autologous chondrocyte implantation in athletes. Clin Sports Med. 2010;29(2):267-282.

48. Niemeyer P, Lenz P, Kreuz PC, et al. Chondrocyte-seeded type I/III collagen membrane for autologous chondrocyte transplantation: prospective 2-year results in patients with cartilage defects of the knee joint. Arthroscopy. 2010;26:1074-1082.

49. Niemeyer P, Pestka JM, Kreuz PC, et al. Characteristic complications after autologous chondrocyte implantation for cartilage defects of the knee joint. Am J Sports Med. 2008;36(11):2091-2099.

50. Peterson L, Brittberg M, Kiviranta I, Akerlund EL, Lindahl A. Autologous chondrocyte transplantation: biomechanics and long-term durability. Am J Sports Med. 2002;30(1):2-12.

51. Peterson L, Minas T, Brittberg M, Nilsson A, Sjogren-Jansson E, Lindahl A. Two- to 9-year outcome after autologous chondrocyte transplantation of the knee. Clin Orthop Relat Res. 2000;374:212-234.

52. Pollock ML, Gaesser GA, Butcher JD, et al. ACSM Position Stand: the recommended quantity and quality of exercise for developing and maintaining cardiorespiratory and muscular fitness, and flexibility in healthy adults. Med Sci Sports Exerc. 1998;30(6):975-991.
53. Radkowski CA, Pietrobon R, Vail TP, Nunley JA 2nd, Jain NB, Easley ME. Cryotherapy temperature differences after total knee arthroplasty: a prospective randomized trial. J Surg Orthop Adv. 2007;16(2):67-72.

54. Raynor MC, Pietrobon R, Guller U, Higgins LD. Cryotherapy after ACL reconstruction: a meta-analysis. J Knee Surg. 2005;18(2):123-129.

55. Reinold MM, Wilk KE, Macrina LC, Dugas JR, Cain EL. Current concepts in the rehabilitation following articular cartilage repair procedures in the knee. J Orthop Sports Phys Ther. 2006;36(10):774-794.

56. Riegger-Krugh CL, McCarty EC, Robinson MS, Wegzyn DA. Autologous chondrocyte implantation: current surgery and rehabilitation. Med Sci Sports Exerc. 2008;40(2):206-214.

57. Roberts D, Ageberg E, Andersson G, Friden T. Effects of short-term cycling on knee joint proprioception in healthy young persons. $A m \mathrm{~J}$ Sports Med. 2003;31(6):990-994.

58. Robertson WB, Fick D, Wood DJ, Linklater JM, Zheng MH, Ackland TR. MRI and clinical evaluation of collagen-covered autologous chondrocyte implantation (CACl) at two years. Knee. 2007;14(2): 117-127.

59. Rodrigo J SJ, Steadman JR, Silliman J, Fulsone HW: Improvement of full-thickness chondral defect healing in the human knee after debridement and microfracture using continuous passive motion. Am J Knee Surg. 1994;7:109-116.

60. Slemenda C, Brandt KD, Heilman DK, et al. Quadriceps weakness and osteoarthritis of the knee. Ann Intern Med. 1997;127(2):97-104.

61. Slemenda C, Heilman DK, Brandt KD, et al. Reduced quadriceps strength relative to body weight: a risk factor for knee osteoarthritis in women? Arthritis Rheum. 1998;41(11):1951-1959.

62. Sohn DH, Lottman LM, Lum LY, et al. Effect of gravity on localization of chondrocytes implanted in cartilage defects. Clin Orthop Relat Res. 2002;394:254-262.

63. Steinwachs M. New technique for cell-seeded collagen matrix-supported autologous chondrocyte transplantation. Arthroscopy. 2009;25(2):208-211.

64. Steinwachs M, Kreuz PC. Autologous chondrocyte implantation in chondral defects of the knee with a type I/III collagen membrane: a prospective study with a 3-year follow-up. Arthroscopy. 2007;23(4):381-387.

65. Steinwachs MR, Kreuz PC. Clinical results of autologous chondrocyte transplantation (ACT) using a collagen membrane. In: Henrich C, Nöth U, Eulert J, eds. Cartilage Surgery and Future Perspectives. Berlin, Germany: Springer; 2003:37-48.

66. Suter E, Herzog W. Does muscle inhibition after knee injury increase the risk of osteoarthritis? Exerc Sport Sci Rev. 2000;28(1):15-18.

67. Vanwanseele B, Lucchinetti E, Stussi E. The effects of immobilization on the characteristics of articular cartilage: current concepts and future directions. Osteoarthritis Cartilage. 2002;10(5):408-419.

68. Voss JR, Lu Y, Edwards RB, Bogdanske JJ, Markel MD. Effects of thermal energy on chondrocyte viability. Am J Vet Res. 2006;67(10): 1708-1712.

69. Wondrasch B, Zak L, Welsch GH, Marlovits S. Effect of accelerated weightbearing after matrix-associated autologous chondrocyte implantation on the femoral condyle on radiographic and clinical outcome after 2 years: a prospective, randomized controlled pilot study. Am J Sports Med. 2009;37(Suppl 1):88S-96S. 